\title{
BMJ Open Trends and determinants of home delivery in Ethiopia: further multivariate decomposition analysis of 2005-2016 Ethiopian Demographic Health Surveys
}

\author{
Sofonyas Abebaw Tiruneh (1) ,' Ayenew Molla Lakew (1) ,2 \\ Seblewongel Tigabu Yigizaw, ${ }^{2}$ Malede Mequanent Sisay, ${ }^{2}$ \\ Zemenu Tadesse Tessema ${ }^{2}$
}

To cite: Tiruneh SA, Lakew AM, Yigizaw ST, et al. Trends and determinants of home delivery in Ethiopia: further multivariate decomposition analysis of 2005-2016 Ethiopian Demographic Health Surveys. BMJ Open 2020;10:e034786. doi:10.1136/ bmjopen-2019-034786

- Prepublication history for this paper is available online. To view these files, please visit the journal online (http://dx.doi. org/10.1136/bmjopen-2019034786).

Received 08 0ctober 2019

Revised 23 June 2020

Accepted 26 June 2020

Check for updates

(c) Author(s) (or their employer(s)) 2020. Re-use permitted under CC BY-NC. No commercial re-use. See rights and permissions. Published by BMJ.

${ }^{1}$ Department of Public Health, College of Health Sciences,

Debre Tabor University, Debre Tabor, Ethiopia

${ }^{2}$ Department of Epidemiology and Biostatistics, Institute of Public Health, College of Medicine and Health Sciences, University of Gondar, Gondar, Ethiopia

Correspondence to Sofonyas Abebaw Tiruneh; zephab2@gmail.com

\section{ABSTRACT}

Objective This study aimed to assess the trends and factors that had contributed to the change in home delivery in Ethiopia over the last decade.

Design, setting and analysis A nationally representative repeated cross-sectional survey was conducted using 2005, 2011 and 2016 Ethiopian Demographic and Health Surveys. Multivariate decomposition logistic regression analysis was employed to identify significant factors that have been contributed to the change in home delivery. Level of statistical significance was declared at a twosided $p$ value $<0.05$.

Outcome measure Trends of home delivery. Participants A total of 33482 women were included. Results Home delivery has been decreased by $21 \%$ over the last decade in Ethiopia. In the last decade, $39 \%$ of the decrements in home delivery attributed to change in women's compositional characteristics. Antenatal care visits, educational status of the women and husband, birth order, religion, wealth index and distance from a health facility were the main sources of compositional change factors for the change of home delivery. Behavioural changes towards health facility delivery contributed approximately two-thirds of the decline of home delivery in Ethiopia. Antenatal care visits, birth order and religion have significantly contributed to the change of home delivery resulted from behavioural changes towards healthcare facility utilisation over the last decade.

Conclusion Despite the importance of health facility delivery, a significant number of women still deliver at home in Ethiopia. Women's compositional characteristics and behaviour changes were significantly associated with the change in home delivery. Multisectoral educational intervention is needed to change women's attitudes towards home delivery. Antenatal care coverage and healthcare facility coverage should increase thereby to improve healthcare facility based-delivery practice. Further research needs to be done to explore the potential barriers of health facility delivery from a religious perspective.
Strengths and limitations of this study

- To the best of our knowledge, this study is first of its kind that identifies the trend contributions of factors to the change in home delivery in Ethiopia.

- We used three waves of Ethiopian Demographic and Health Surveys, which are nationally representative data that could enhance the generalisability of the findings.

- Besides, this multivariate decomposition logistic regression analysis used to identify factors that positively or negatively contributed to the decline of home delivery in Ethiopia could help policymakers and health planners to design potential interventions.

- However, since data were collected using selfreported interview, this might prone to recall and social desirability bias.

\section{INTRODUCTION}

Every day, >800 women die from preventable causes related to pregnancy and childbirth, and almost all deaths occur in low-income andmiddle-income countries. ${ }^{1}$ Worldwide, maternal mortality fell from 385 deaths per 100000 live births in 1990 to 216 deaths in 2015, in other words, $44 \%$ of deaths were averted. ${ }^{23}$ Even though in the last two and half decades maternal mortality had declined, it is not still in acceptable spectrum in Ethiopia and other low-income andmiddle-income countries. ${ }^{34}$ In Ethiopia, the trends of maternal mortality declined 1250 to 353/100000 live births between 1990 and 2015, which reflects maternal mortality was reduced by less than three-fourth below the target of the Millennium Development Goals (MDGs). ${ }^{5}$ Furthermore, Sustainable Development Goal (SDG) 3, target 3.1 calls 
for the reduction of maternal mortality ratio less than 70 per 100000 live births between 2016 and $2030 .^{7}$

Studies evidenced that nearly $33 \%$ of maternal death occurred in the subacute and delayed postpartum period, $25 \%$ in the antepartum period, another $25 \%$ in the intrapartum and immediate postpartum periods and $12 \%$ in the late postpartum period. ${ }^{8}$ However, numerous factors contribute to high maternal mortality ratio. Most maternal deaths are contributed by direct obstetric complications such as haemorrhage, pregnancy-induced hypertension, sepsis and obstructed labour collectively accounts for $64 \%$ of maternal death. Besides, poverty, limited access to healthcare, unskilled childbirth and maternal sociodemographic characteristics are among the indirect causes of maternal mortality. ${ }^{9-11}$ Even though skilled birth attendance can save the lives of women, only $59 \%$ of births were attended by skilled birth attendants between 2012 and 2017 in sub-Saharan Africa. ${ }^{12}$ High load of home delivery in Ethiopia is a precipitating factor for high maternal mortality ratio. For example, the magnitude of home delivery was $94.5 \%$ in $2000,93.1 \%$ in $2005,87.9 \%$ in 2011 and $73.6 \%$ in 2016 , which are unacceptably high. ${ }^{13} 14$

According to different studies, maternal health service utilisation was low due to low educational status, cultural and communal factors, limited access to health facilities, poor quality of care, lack of roads and poor wealth status in Ethiopia. ${ }^{13-17}$ On the other hand, taking at least one antenatal care visit, multiparity, being educated women, being urban resident, husband's positive attitude towards health facility delivery, easy access to health facilities and having good wealth status were reported in the contribution of health facility-based delivery in Ethiopia. ${ }^{17-20}$ However, between 2005 and 2016, the trends of home delivery show decrements, no evidence which factors have contributed to the observed reduction in the last decade.

Therefore, this multivariate decomposition logistic analysis aimed to assess the trends and factors that either positively or negatively contributed to the change for home delivery in Ethiopia. This study is anticipated to provide data for health planners and policymakers in planning for further reduction of home delivery thereby to decrease maternal mortality in Ethiopia and elsewhere in low-income andmiddle-income countries.

\section{METHODS AND MATERIALS}

\section{Study design, area and period}

The nationally representative repeated cross-sectional study design was employed using 2005, 2011 and 2016 Ethiopian Demographic and Health Surveys (EDHS). Ethiopia is laying between latitude $3^{\circ}$ and $14^{\circ} \mathrm{N}$ and longitude $33^{\circ}$ and $48^{\circ} \mathrm{E}$ in the horn of Africa. Ethiopia has a total area of $1100000 \mathrm{~km}^{2}$ and structured in nine regional states, namely Tigray, Afar, Amhara, Benishangul-Gumuz, Gambela, Harari, Oromia, Somali and Southern Nations Nationalities and Peoples of Region and two city administration (Addis Ababa and Dire Dawa).

\section{Source and study population}

The source population were all reproductive age group women who gave birth 5 years preceding each survey. The study population were all reproductive-age group women who gave birth 5 years preceding each survey in the selected enumeration areas (EAs). In each survey, a nationally representative sample of 10721 in 2005, 11872 in 2011 and 10889 in 2016 weighted number of women participated. Recorded data were accessed at www.messdhs.com on request with the assistance of ICF International.

\section{Data collection tools and procedures}

Data were collected in two stages in each survey years. Stratification was also made as urban and rural in each region of the country. In the first stage, 540, 624 and 645 EAs were selected in 2005, 2011 and 2016 EDHS, respectively. In the second stage, a fixed number of households were selected in each EAs for each survey using systematic sampling. The detailed sampling procedure is available in the EDHS reports from the Measure DHS website (www. dhsprogram.com) for each specific survey.

\section{Outcome variable}

The outcome variable was taken as a binary response; a woman gave birth at home coded as home delivery, and women who gave birth at health facilities (government, private and non-government) were taken as health facility delivery.

\section{Independent variables}

All sociodemographic and obstetric characteristics were taken as independent variables for the three consecutive surveys.

\section{Patient and public involvement}

As the study conducted based on secondary data, therefore, there is no patient and the public involvement in this study.

\section{Statistical analysis}

The data were cleaned and analysed using STATA software (V.14.1). Sample weighting was done for further analysis. Descriptive statistics were also done for the description of the variables. A multivariate decomposition logistic regression analysis was employed to identify the contributions of group differences to average predictions. ${ }^{21}$ The purpose of this decomposition analysis was to identify factors that contributed to the change in home delivery in the last decade in Ethiopia.

A non-linear multivariate logit decomposition model was used to identify the contribution of proportion change to home delivery over the last decade. The output from the multivariate decomposition logistic regression analysis had two contribution effects. These effects were the compositional differences (endowments) ' $E$ ' and the effects of characteristics that are the difference in the coefficients or behavioural change ' $\mathrm{C}$ ' responses for the selected predictor variables. In the non-linear model, the 
dependent variable is a function of a linear combination of predictors and regression coefficients:

$\mathrm{Y}=\mathrm{F}(\mathrm{X} \beta)=\operatorname{logit}(\mathrm{Y})=\mathrm{X} \beta$, where $\mathrm{Y}$ denotes the $\mathrm{n} \times 1$ dependent variable vector, $\mathrm{X}$ an $\mathrm{n} \times \mathrm{K}$ matrix of independent variables and $\beta$ a $K \times 1$ vector of coefficients.

The proportion difference in $\mathrm{Y}$ between survey $\mathrm{A}$ and survey B of successive EDHS surveys of home delivery can be decomposed as:

$\mathrm{Y}_{\mathrm{A}}-\mathrm{Y}_{\mathrm{B}}=\mathrm{F}\left(\mathrm{X}_{\mathrm{A}} \beta_{\mathrm{A}}\right)-\mathrm{F}\left(\mathrm{X}_{\mathrm{B}} \beta_{\mathrm{B}}\right)$

For the log odds of home delivery, the proportion of the model is written as

$$
\begin{aligned}
\text { Logit } & \left(\mathrm{Y}_{\mathrm{A}}\right)-\operatorname{logit}\left(\mathrm{Y}_{\mathrm{B}}\right)=\mathrm{F}\left(\mathrm{X}_{\mathrm{A}} \beta_{\mathrm{A}}\right)-\mathrm{F}\left(\mathrm{X}_{\mathrm{B}} \beta_{\mathrm{B}}\right) \\
= & \underbrace{\mathrm{F}\left(\mathrm{X}_{\mathrm{A}} \beta_{\mathrm{A}}\right)-\mathrm{F}\left(\mathrm{X}_{\mathrm{B}} \beta_{\mathrm{A}}\right)}_{\mathrm{E}}+\underbrace{F\left(X_{B} \beta_{A}\right)-F\left(X_{B} \beta_{B}\right)}_{\mathrm{C}}
\end{aligned}
$$

The component ' $\mathrm{E}$ ' is the difference attributable to endowment change, usually called the explained component. The ' $\mathrm{C}$ ' component is the difference attributable to coefficients (behavioural) change, usually called the unexplained component.

The model structure for the decomposition analysis was:

Logit (A)-Logit (B) $=\left[\beta_{0 \mathrm{~A}}-\beta_{0 \mathrm{~B}}\right]+\Sigma \beta_{\mathrm{ijA} A} \quad\left[\mathrm{X}_{\mathrm{ij} \mathrm{A}}-\mathrm{X}_{\mathrm{ij} \mathrm{B}}\right]+\Sigma \mathrm{X}_{\mathrm{ijB}}$ $\left[\beta_{\mathrm{ijA}}-\beta_{\mathrm{ijB}}\right]$, where

- $\beta_{0 \mathrm{~A}}$ is the intercept in the regression equation for EDHS 2016.

- $\beta_{\text {ов }}$ is the intercept in the regression equation for EDHS 2005.

- $\beta_{\mathrm{ijA}}$ is the coefficient of the $\mathrm{j}^{\text {th }}$ category of the $\mathrm{i}^{\text {th }}$ determinant for EDHS 2016.

- $\beta_{\mathrm{ijB}}$ is the coefficient of the $\mathrm{j}^{\text {th }}$ category of the $\mathrm{i}^{\text {th }}$ determinant for EDHS 2005.

- $\mathrm{X}_{\mathrm{ijA}}$ is the proportion of the $\mathrm{j}^{\text {th }}$ category of the $\mathrm{i}^{\text {th }}$ determinant for EDHS 2016.

- $\mathrm{X}_{\mathrm{ij \textrm {B }}}$ is the proportion of the $\mathrm{j}^{\text {th }}$ category of the $\mathrm{i}^{\text {th }}$ determinant for EDHS 2005.

\section{RESULTS}

\section{Background characteristics of women}

Table 1 depicts the distribution of individual characteristics of women who gave birth in 5 years preceding each survey in 2005, 2011 and 2016. In the three consecutive surveys, $>60 \%$ of the women were in the age group of 20-34 years. Besides, women had almost the same mean age of $29( \pm 6.6 \mathrm{SD})$ years. As well, a significant number $(48 \%)$ of female household heads were observed in the 2011 EDHS report. Almost all $(>90 \%)$ of the women were married 5 years preceding each survey; $79 \%, 69 \%$ and $66 \%$ of the women in each EDHS were unable to read and write, respectively (table 1 ).

\section{Trends of home delivery during the survey period}

The trend of home delivery over the study period (2005-2016) showed a significant decline, which is decreased from $94.20 \%$ in 2005 to $73.44 \%$ in 2016. The largest decline was observed in the survey period 2011-2016 with a 17\% drop down and in the survey period, 2005-2011 decreased from 94 to 90 , which is a $4 \%$ decline (figure 1 ).
Table 1 Sociodemographic and obstetrics characteristics of the women in 2005, 2011 and 2016 EDHS

\section{Percentage distribution for each}

\begin{tabular}{|c|c|c|c|}
\hline $\begin{array}{l}\text { Characteristics of } \\
\text { women }\end{array}$ & $\begin{array}{l}\text { EDHS } 2005 \\
n=10721\end{array}$ & $\begin{array}{l}\text { EDHS } 2011 \\
\mathrm{n}=11872\end{array}$ & $\begin{array}{l}\text { EDHS } 2016 \\
\mathrm{n}=10889\end{array}$ \\
\hline \multicolumn{4}{|c|}{ Mother's age (years) } \\
\hline$<20$ & 12.26 & 9.33 & 7.81 \\
\hline $20-34$ & 62.07 & 66.22 & 67.38 \\
\hline $35-49$ & 25.67 & 24.25 & 24.80 \\
\hline Mean \pm SD & $29.01 \pm 6.95$ & $29.04 \pm 6.63$ & $29.23 \pm 6.53$ \\
\hline \multicolumn{4}{|l|}{ Household head } \\
\hline Male & 89.15 & 51.5 & 86.06 \\
\hline Female & 10.85 & 48.05 & 13.94 \\
\hline \multicolumn{4}{|l|}{ Marital status } \\
\hline $\begin{array}{l}\text { Not having } \\
\text { partner }\end{array}$ & 4.56 & 6.07 & 6.25 \\
\hline Had partner & 95.44 & 93.93 & 93.75 \\
\hline
\end{tabular}
survey

Religion

\begin{tabular}{llll} 
Orthodox & 42.37 & 38.06 & 34.14 \\
\hline Muslim & 35.00 & 35.49 & 41.50 \\
\hline $\begin{array}{l}\text { Protestant } \\
\text { Others }\end{array}$ & 19.95 & 23.23 & 21.09 \\
$\begin{array}{l}\text { Women educational level } \\
\text { Unable to read }\end{array}$ & 79.31 & 3.22 & 3.26 \\
and write & 69.30 & 66.13 \\
$\begin{array}{l}\text { Primary } \\
\text { education }\end{array}$ & 16.53 & 27.5 & 26.67 \\
$\begin{array}{l}\text { Secondary } \\
\text { education }\end{array}$ & 3.79 & 2.24 & 4.68 \\
$\begin{array}{l}\text { Higher education } \\
\text { Husband educational level }\end{array}$ & 0.38 & 1.42 & 2.52 \\
$\begin{array}{l}\text { Unable to read } \\
\text { and write }\end{array}$ & 59.03 & 50.60 & 48.57 \\
$\begin{array}{l}\text { Primary } \\
\text { education }\end{array}$ & 30.37 & 41.26 & 39.21 \\
$\begin{array}{l}\text { Secondary } \\
\text { education }\end{array}$ & 9.58 & 4.95 & 7.65 \\
\hline
\end{tabular}

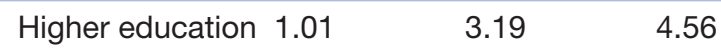

Women occupation

$\begin{array}{llll}\text { Not working } & 71.11 & 47.14 & 55.62 \\ \text { Working } & 28.89 & 52.86 & 44.35\end{array}$

Husband occupation

\begin{tabular}{|crll} 
Not working & 2.00 & 1.33 & 56.93 \\
\hline $\begin{array}{l}\text { Working } \\
\text { Health institution }\end{array}$ & 98.00 & 98.67 & 43.07 \\
\hline $\begin{array}{l}\text { Big problem } \\
\text { Big a big }\end{array}$ & 74.40 & 75.43 & 60.58 \\
$\begin{array}{l}\text { Not a big } \\
\text { problem }\end{array}$ & 25.60 & 24.57 & 39.42 \\
\hline
\end{tabular}

Had ANC 
Table 1 Continued

\begin{tabular}{|c|c|c|c|}
\hline \multirow[b]{2}{*}{$\begin{array}{l}\text { Characteristics of } \\
\text { women }\end{array}$} & \multicolumn{3}{|c|}{$\begin{array}{l}\text { Percentage distribution for each } \\
\text { survey }\end{array}$} \\
\hline & $\begin{array}{l}\text { EDHS } 2005 \\
n=10721\end{array}$ & $\begin{array}{l}\text { EDHS } 2011 \\
n=11872\end{array}$ & $\begin{array}{l}\text { EDHS } 2016 \\
n=10889\end{array}$ \\
\hline No & 71.86 & 57.45 & 37.42 \\
\hline Yes & 28.14 & 42.55 & 62.58 \\
\hline \multicolumn{4}{|l|}{ Birth order } \\
\hline 1 & 17.13 & 19.05 & 18.65 \\
\hline $2-4$ & 42.90 & 43.62 & 42.80 \\
\hline$\geq 5^{+}$ & 39.97 & 37.33 & 38.55 \\
\hline \multicolumn{4}{|l|}{ Parity } \\
\hline$\leq 2$ & 26.10 & 29.22 & 28.80 \\
\hline $2-5$ & 40.05 & 39.67 & 39.67 \\
\hline$\geq 5^{+}$ & 33.85 & 31.11 & 31.53 \\
\hline \multicolumn{4}{|l|}{ Wealth index } \\
\hline Poor & 42.98 & 45.22 & 46.76 \\
\hline Middle & 22.44 & 20.53 & 20.60 \\
\hline Richer & 34.58 & 34.26 & 32.64 \\
\hline \multicolumn{4}{|l|}{ Residence } \\
\hline Urban & 7.09 & 12.87 & 11.14 \\
\hline Rural & 92.91 & 87.13 & 88.86 \\
\hline \multicolumn{4}{|l|}{ Region } \\
\hline Tigray & 6.39 & 6.34 & 6.44 \\
\hline Afar & 0.97 & 1.02 & 1.05 \\
\hline Amhara & 23.99 & 22.37 & 18.74 \\
\hline Oromia & 39.69 & 42.23 & 44.20 \\
\hline Somali & 4.24 & 3.07 & 4.66 \\
\hline Benishangul & 0.78 & 1.18 & 1.11 \\
\hline SNNPR & 21.81 & 21.01 & 20.67 \\
\hline Gambela & 0.27 & 0.34 & 0.24 \\
\hline Harari & 0.19 & 0.24 & 0.24 \\
\hline Addis Ababa & 1.32 & 1.87 & 2.23 \\
\hline Dire Dawa & 0.34 & 0.33 & 0.42 \\
\hline
\end{tabular}

ANC, antenatal care; EDHS, Ethiopian Demographic and Health Surveys; SNNPR, Southern Nations Nationalities and Peoples of Region.

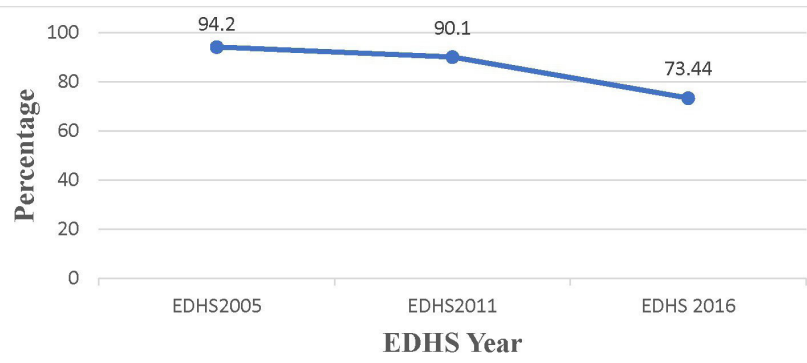

Figure 1 The trend of home delivery from 2005 to 2016 Ethiopian Demographic and Health Surveys (EDHS) 5 years preceding each survey year.
The rate of decline in home delivery from 2005 to 2016 varied in terms of different factors. For example, the reduction in the stated period was the highest $(52 \%)$ in the Tigray Regional State and the lowest $(11 \%)$ in the Afar Regional State of Ethiopia. Besides, the decline was higher $(36.34 \%)$ in urban and lower $(17.60 \%)$ in rural settlements. The trend was declined by $29 \%$ among women who received antenatal care services during pregnancy (table 2).

\section{Detailed multivariate decomposition logistic regression analysis \\ Difference due to characteristics (endowment)}

This multivariate decomposition logistic regression analysis revealed that about $39 \%$ of the overall change in home delivery was due to differences in compositional characteristics. Among the compositional change factors antenatal care visits, religion, education of women and husband, birth order, wealth index, distance from health facilities and residence had a statistically significant effect on the change contribution (table 3 ).

Women who had at least one antenatal care visit during pregnancy were more likely to deliver at the health facility. The coverage of antenatal care visit was increased from $28 \%$ to $62 \%$ in the last decade (table 1), that had an important compositional contribution to the decline of home delivery by $35 \%$.

Followers of the Protestant sect were more likely to give birth at home than Orthodox Christians. As a result, the increase in the proportion of the Protestant sect followers (table 1) had a significant rise to home delivery in the last decade. Keeping all other variables constant, the improvement of women's educational status to primary school complete and above before the survey (table 1) had a positive significant contribution to the decline of the trend.

A decrease in the composition of husband's secondary education level during the surveys (table 1) hurt on the place of delivery, whereas a rise in the proportion of husbands with higher education had a positive contribution to the decline of home delivery.

Keeping the coefficient characteristics constant, women who had no significant compositional change in the category of birth order between two and four (table 1) had a contribution to the change of home delivery. On the other hand, a decrease in the number of women who had more than five birth order had a positive contribution to the decline of home delivery in the last decade (table 3 ).

The decline in the proportion of rich wealth status women in the last decade increased the prevalence of home delivery. Accessibility of health facilities had a positive contribution in decreasing home delivery by $2 \%$ over the last decade. Women living in rural areas had a high risk of giving birth at home. As shown in table 1, the composition change of rural residence was minimal; this insignificant compositional change significantly increases the prevalence of home delivery over the last decade (table 3). 
Table 2 Trends of home delivery among women who gave birth preceding the survey by women characteristics, 2005, 2011 and 2016 EDHS

\begin{tabular}{|c|c|c|c|c|c|c|}
\hline \multirow[b]{2}{*}{ Individual variables } & \multirow{2}{*}{$\begin{array}{l}\text { EDHS } 2005 \\
\mathrm{n}=10721\end{array}$} & \multirow{2}{*}{$\begin{array}{l}\text { EDHS } 2011 \\
\mathrm{n}=11872\end{array}$} & \multirow{2}{*}{$\begin{array}{l}\text { EDHS } 2016 \\
\mathrm{n}=10889\end{array}$} & \multicolumn{3}{|c|}{ Percentage point difference in home delivery } \\
\hline & & & & 2011-2005 & 2016-2011 & 2016-2005 \\
\hline \multicolumn{7}{|l|}{ Mother's age (years) } \\
\hline$<20$ & 93.95 & 91.16 & 64.97 & -2.79 & -26.19 & -28.98 \\
\hline $20-34$ & 94.16 & 88.49 & 72.33 & -5.67 & -16.16 & -21.83 \\
\hline $35-49$ & 96.67 & 93.91 & 79.14 & -2.76 & -14.77 & -17.53 \\
\hline \multicolumn{7}{|l|}{ Household head } \\
\hline Male & 95.51 & 90.20 & 74.55 & -5.31 & -15.65 & -20.96 \\
\hline Female & 88.77 & 89.90 & 66.59 & 1.13 & -23.31 & -22.18 \\
\hline \multicolumn{7}{|l|}{ Marital status } \\
\hline Had not a partner & 90.51 & 86.17 & 66.06 & -4.34 & -20.11 & -24.45 \\
\hline Had partner & 94.99 & 90.31 & 73.94 & -4.68 & -16.37 & -21.05 \\
\hline \multicolumn{7}{|l|}{ Religion } \\
\hline Orthodox & 92.70 & 84.63 & 79.91 & -8.07 & -4.72 & -12.79 \\
\hline Muslim & 97.09 & 93.60 & 79.76 & -3.49 & -13.84 & -17.33 \\
\hline Protestant & 94.69 & 92.90 & 75.45 & -1.79 & -17.45 & -19.24 \\
\hline Others & 98.26 & 94.58 & 90.42 & -3.68 & -4.16 & -7.84 \\
\hline \multicolumn{7}{|l|}{ Women education } \\
\hline Illiterate & 97.79 & 95.26 & 83.91 & -2.53 & -11.35 & -13.88 \\
\hline Primary education & 92.22 & 85.05 & 62.65 & -7.17 & -22.4 & -29.57 \\
\hline Secondary education & 50.58 & 30.41 & 22.03 & -20.17 & -8.38 & -28.55 \\
\hline Higher education & 18.20 & 24.47 & 8.53 & 6.27 & -15.94 & -9.67 \\
\hline \multicolumn{7}{|l|}{ Husband education } \\
\hline Illiterate & 98.29 & 95.74 & 83.03 & -2.55 & -12.71 & -15.26 \\
\hline Primary education & 95.20 & 89.95 & 75.53 & -5.25 & -14.42 & -19.67 \\
\hline Secondary education & 78.17 & 64.99 & 39.61 & -13.18 & -25.38 & -38.56 \\
\hline Higher education & 37.94 & 45.05 & 19.06 & 7.11 & -25.99 & -18.88 \\
\hline \multicolumn{7}{|l|}{ Women occupation } \\
\hline Not working & 94.95 & 90.23 & 76.05 & -4.72 & -14.18 & -18.9 \\
\hline Working & 94.36 & 89.90 & 70.18 & -4.46 & -19.72 & -24.18 \\
\hline \multicolumn{7}{|l|}{ Husband occupation } \\
\hline Not working & 65.89 & 89.81 & 75.61 & 23.92 & -14.2 & 9.72 \\
\hline Working & 95.37 & 90.06 & 70.58 & -5.31 & -19.48 & -24.79 \\
\hline \multicolumn{7}{|l|}{ Health facility distance } \\
\hline Big problem & 96.97 & 94.36 & 82.13 & -2.61 & -12.23 & -14.84 \\
\hline Not a big problem & 88.43 & 76.83 & 60.10 & -11.6 & -16.73 & -28.33 \\
\hline \multicolumn{7}{|l|}{ Had ANC } \\
\hline No & 98.19 & 96.88 & 91.50 & -1.31 & -5.38 & -6.69 \\
\hline Yes & 82.34 & 76.64 & 53.68 & -5.7 & -22.96 & -28.66 \\
\hline \multicolumn{7}{|l|}{ Birth order } \\
\hline 1 & 86.83 & 79.04 & 51.01 & -7.79 & -28.03 & -35.82 \\
\hline $2-4$ & 95.01 & 90.19 & 72.94 & -4.82 & -17.25 & -22.07 \\
\hline$\geq 5$ & 97.94 & 95.51 & 84.85 & -2.43 & -10.66 & -13.09 \\
\hline \multicolumn{7}{|l|}{ Parity } \\
\hline$\leq 2$ & 87.89 & 80.62 & 52.83 & -7.27 & -27.79 & -35.06 \\
\hline
\end{tabular}

Continued 
Table 2 Continued

\begin{tabular}{|c|c|c|c|c|c|c|}
\hline \multirow[b]{2}{*}{ Individual variables } & \multirow{2}{*}{$\begin{array}{l}\text { EDHS } 2005 \\
\mathrm{n}=10721\end{array}$} & \multirow{2}{*}{$\begin{array}{l}\text { EDHS } 2011 \\
\mathrm{n}=11872\end{array}$} & \multirow{2}{*}{$\begin{array}{l}\text { EDHS } 2016 \\
\mathrm{n}=10889\end{array}$} & \multicolumn{3}{|c|}{ Percentage point difference in home delivery } \\
\hline & & & & 2011-2005 & 2016-2011 & 2016-2005 \\
\hline $2-5$ & 94.52 & 92.29 & 78.06 & -2.23 & -14.23 & -16.46 \\
\hline$\geq 5^{+}$ & 98.03 & 96.06 & 86.45 & -1.97 & -9.61 & -11.58 \\
\hline \multicolumn{7}{|l|}{ Wealth status } \\
\hline Poor & 99.08 & 97.38 & 85.29 & -1.7 & -12.09 & -13.79 \\
\hline Middle & 98.14 & 96.87 & 77.39 & -1.27 & -19.48 & -20.75 \\
\hline Rich & 87.26 & 76.31 & 53.98 & -10.95 & -22.33 & -33.28 \\
\hline \multicolumn{7}{|l|}{ Residence } \\
\hline Urban & 56.94 & 50.18 & 20.60 & -6.76 & -29.58 & -36.34 \\
\hline Rural & 97.67 & 95.95 & 80.07 & -1.72 & -15.88 & -17.6 \\
\hline \multicolumn{7}{|l|}{ Region } \\
\hline Tigray & 94.12 & 88.36 & 41.87 & -5.76 & -46.49 & -52.25 \\
\hline Afar & 95.95 & 93.19 & 85.28 & -2.76 & -7.91 & -10.67 \\
\hline Amhara & 96.49 & 89.82 & 72.46 & -6.67 & -17.36 & -24.03 \\
\hline Oromia & 95.75 & 92.00 & 81.10 & -3.75 & -10.9 & -14.65 \\
\hline Somali & 95.23 & 92.40 & 82.07 & -2.83 & -10.33 & -13.16 \\
\hline Benishangul & 94.67 & 90.89 & 74.04 & -3.78 & -16.85 & -20.63 \\
\hline SNNPR & 96.30 & 93.79 & 73.95 & -2.51 & -19.84 & -22.35 \\
\hline Gambela & 84.26 & 72.48 & 54.38 & -11.78 & -18.1 & -29.88 \\
\hline Harari & 68.20 & 67.63 & 49.59 & -0.57 & -18.04 & -18.61 \\
\hline Addis Ababa & 21.84 & 17.66 & 2.98 & -4.18 & -14.68 & -18.86 \\
\hline Dire Dawa & 74.90 & 60.27 & 42.81 & -14.63 & -17.46 & -32.09 \\
\hline \multirow[t]{2}{*}{ Prevalence $95 \% \mathrm{Cl}$} & 95 & 90 & 73 & -5 & -17 & -22 \\
\hline & 94.3 to 95.2 & 89.5 to 90.6 & 72.6 to 74.3 & -4.8 to -4.6 & -16.9 to -16.3 & -21.7 to -20.9 \\
\hline
\end{tabular}

ANC, antenatal care; EDHS, Ethiopian Demographic and Health Surveys; SNNPR, Southern Nations Nationalities and Peoples of Region.

\section{Difference due to effects of coefficient}

Controlling the roles of change in compositional characteristics, more than two-thirds $(61 \%)$ of home delivery was declined resulted from behavioural changes towards health facility delivery (table 3 ). Antenatal care visits, religion and birth order had statistically significant effects of coefficient contribution to the observed change in home delivery. Controlling all compositional change factors, $4 \%$ of the home delivery was declined due to the change in the behaviour of health facility delivery among the antenatal care service visitors over the last decade. Keeping compositional change factors constant, women protestant sect flowers hurt the contribution to home delivery over the past decade.

Furthermore, about 25\% of the decrement of home delivery over the last decade was resulted from changes in health facility delivery utilisation behaviour among women who had a birth order two and above (table 3 ).

\section{Discussion}

Women giving birth at health facilities can prevent maternal deaths through getting skilled birth attendance, drugs to address labour complications and referrals to more advanced health facilities. ${ }^{22}$ Still, a significant number of women give birth at home however giving birth at health facilities has an invaluable effect in reducing pregnancy-related complications and deaths among women in the reproductive age group. The present study tried to identify the factors that have been contributed to the change in home delivery during the last decade in Ethiopia.

Multivariate decomposition logistic regression analysis relaxes non-linear models comparable to previous decomposition analysis models. ${ }^{23-25}$ Previous studies were conducted to identify factors that affect home delivery. To the best of our knowledge, there are no studies have been conducted on the place of delivery change through significant factors. This method of analysis was used to examine the trends of home delivery and identify factors that either positively or negatively contributed to the change of home delivery.

Home delivery in Ethiopia declined by around 21\% over the last decade, mainly between 2011 and 2016 survey years. This could be due to the launching of the Health Extension Programme and improving access to 
Table 3 Multivariate logistic regression decomposition analysis of home delivery women who gave birth in the last 10 years preceding 2005-2016 EDHS, Ethiopia

\begin{tabular}{|c|c|c|c|c|}
\hline \multirow[b]{2}{*}{ Variables } & \multicolumn{2}{|l|}{ Difference due to characteristics (E) } & \multicolumn{2}{|l|}{ Difference due to coefficient (C) } \\
\hline & Coeff $(95 \% \mathrm{Cl})$ & Pct. & Coeff $(95 \% \mathrm{Cl})$ & Pct. \\
\hline \multicolumn{5}{|l|}{ Age (years) } \\
\hline $20-34$ & $-0.0026425(-0.0065794$ to 0.0012943$)$ & 1.2078 & $0.0097217(-0.020772$ to 0.026531$)$ & -1.316 \\
\hline $35-49$ & $0.00015715(-0.000019082$ to 0.00033337$)$ & -0.0718 & $0.0028792(-0.0053135$ to 0.024757$)$ & -4.4434 \\
\hline Muslim & $0.0011654(-0.00043086$ to 0.0027617$)$ & -0.53266 & $0.0019208(-0.0071241$ to 0.010966$)$ & -0.87792 \\
\hline Protestant & $0.0022454(0.0011048 \text { to } 0.0033861)^{*}$ & -1.0263 & $0.0067475(0.00061695 \text { to } 0.012878)^{\star}$ & -3.084 \\
\hline Others & 0.0007805 (0.00022288 to 0.0013381$)$ & -0.35674 & $0.0013868(-0.00087756$ to 0.0036511$)$ & -0.63384 \\
\hline \multicolumn{5}{|l|}{ Women education } \\
\hline Higher & $-0.0030286(-0.0059084 \text { to }-0.00014878)^{*}$ & 1.3843 & $0.00027299(-0.00021235$ to 0.00075833$)$ & -0.1248 \\
\hline \multicolumn{5}{|l|}{ Husband education } \\
\hline No education & 1 & 1 & 1 & 1 \\
\hline Primary & $-0.001852(-0.0045476$ to 0.00084366$)$ & 0.84646 & $0.003113(-0.0053549$ to 0.011581$)$ & -1.4228 \\
\hline Secondary & $0.00084942(0.00042745 \text { to } 0.0012714)^{\star}$ & -0.38824 & $0.0010909(-0.0027474$ to 0.0049291$)$ & -0.4986 \\
\hline Higher & $-0.0052866(-0.0080882 \text { to }-0.0024849)^{*}$ & 2.4163 & $0.00025019(-0.00071622$ to 0.0012166$)$ & -0.11435 \\
\hline \multicolumn{5}{|l|}{ Women occupation } \\
\hline Not working & 1 & 1 & 1 & 1 \\
\hline Working & $0.0006093(-0.011577$ to 0.012796$)$ & -0.27849 & $-0.0015175(-0.014399$ to 0.011364$)$ & $\begin{array}{l}0.69359 \\
0.85821\end{array}$ \\
\hline \multicolumn{5}{|l|}{ Husband occupation } \\
\hline Two to four births & $0.0015601(0.00044295 \text { to } 0.0026773)^{\star}$ & -0.71307 & $-0.01878(-0.033508 \text { to }-0.0040518)^{\star}$ & 8.5835 \\
\hline $\begin{array}{l}\text { Five and above } \\
\text { births }\end{array}$ & $-0.0003622(-0.0006497 \text { to }-0.00007469)^{\star}$ & 0.16555 & $-0.033806(-0.060462 \text { to }-0.0071505)^{*}$ & 15.452 \\
\hline \multicolumn{5}{|l|}{ ANC visit } \\
\hline No & 1 & 1 & 1 & 1 \\
\hline Yes & $-0.076563(-0.088698 \text { to }-0.064428)^{\star}$ & 34.994 & $-0.0081231(-0.016207 \text { to }-0.000039645)^{\star}$ & 3.7127 \\
\hline \multicolumn{5}{|l|}{ Wealth status } \\
\hline Poor & 1 & 1 & 1 & 1 \\
\hline Middle & $0.0007966(-1.2357 \mathrm{e}-06$ to 0.000077712$)$ & -0.01746 & $-0.00020032(-0.0099877$ to 0.009587$)$ & 0.091558 \\
\hline Rich & $-0.000038238(-0.00122 \text { to }-0.00037319)^{*}$ & 0.34409 & $0.013165(0.00021347$ to 1.026117$)$ & -6.0173 \\
\hline \multicolumn{5}{|l|}{ Parity } \\
\hline$<2$ & 1 & 1 & 1 & 1 \\
\hline $2-5$ & $0.00111(-0.0019906$ to 0.00018171$)$ & -0.50733 & $0.0032984(-0.0092389$ to 0.015836$)$ & -1.5076 \\
\hline$>5$ & $-0.00090444(-0.0019906$ to 0.00018171$)$ & 0.41338 & $0.0049123(-0.014804$ to 0.024629$)$ & -2.2452 \\
\hline \multicolumn{5}{|c|}{ Distance health facility } \\
\hline Not big problem & 1 & 1 & 1 & 1 \\
\hline Big problem & $-0.0047901(-0.0085384 \text { to }-0.0010417)^{*}$ & 2.1894 & $-0.001343(-0.0075911$ to 0.0049052$)$ & 0.61381 \\
\hline Residence & & & & \\
\hline
\end{tabular}


Table 3 Continued

\begin{tabular}{|c|c|c|c|c|}
\hline \multirow[b]{2}{*}{ Variables } & \multicolumn{2}{|l|}{ Difference due to characteristics (E) } & \multicolumn{2}{|l|}{ Difference due to coefficient (C) } \\
\hline & Coeff $(95 \% \mathrm{Cl})$ & Pct. & Coeff $(95 \% \mathrm{Cl})$ & Pct. \\
\hline Urban & 1 & 1 & 1 & 1 \\
\hline Constants & & & $-0.15848(-0.23109$ to -0.085858$)$ & 72.433 \\
\hline Overall & $-0.086145(-0.12888 \text { to }-0.043405)^{\star \star}$ & 39.37 & $-0.13264(-0.087914 \text { to }-0.087914)^{\star \star}$ & 60.63 \\
\hline
\end{tabular}

*significance at $\mathrm{P}$-valve $<0.05,{ }^{* *}$ significance at $\mathrm{P}$-valve $<0.01$.

ANC, antenatal care; EDHS, Ethiopian Demographic and Health Surveys; Pct, percentage contribution.

healthcare to meet the primary attention of the MDG agenda. $^{2627}$

This study revealed that the contribution of behaviour (coefficient) changes were more important than that of composition (endowments) changes to the decline of home delivery over the last decade.

Keeping coefficient changes constant, the explained contribution of the change in compositional characteristics to the decline of home delivery was 39\% in Ethiopia. The predominant changes in home delivery were due to the proportion of changes in antenatal care visits. Antenatal coverage increased by $34 \%$ (table 1 ) over the last decade which had a $35 \%$ contribution to the decline of home delivery. The possible reason might be the fact that women who had antenatal follow-up were more likely to deliver at health facilities than those who had no follow-ups. ${ }^{18-31}$

Women having primary school education and above had a positive effect on the decline of home delivery compared with those unable to read and write. This result supported by the evidence that higher educational attainment of women was more likely to give birth at health facilities compared with those unable to read and write. ${ }^{1893233}$ Besides, Ethiopia has been working hard to achieve the MDG agenda that advocates women's education. Also, Ethiopia launched the Growth and Transformation Plan I, which gave special attention to women's education. ${ }^{26}{ }^{34}$ Therefore, the compositional increment in women's education profile in the last decade had a positive contribution to the decline of home delivery in the country.

As well, higher education of husbands had a significant effect in reducing home delivery. Since the decrease in the number of husbands with secondary school education (table 1) had a negative contribution to the decline of home delivery. The possible justification might be that educated husbands knew about the importance of health facility delivery and made decisions on the place of delivery.

Another endowment factor that significantly decreased home delivery was birth order. The increase in the proportion of birth order in the survey period resulted in a decrease in home delivery. This finding supports evidences elsewhere women with high birth order delivered at the health facility. ${ }^{29} 31$ The reason for this finding might be also women with high birth order would have experience with the importance of health facility delivery.

The proportion of Protestant women has increased in the last decade (table 1), which increases home delivery proportion because such women were more likely to deliver at home compared with Orthodox Christian women. However, whether religion can be a barrier to delivery at the health facility, it needs further investigations.

The wealth status of women had a significant effect on home delivery. The proportion of rich wealth status women decreased in the survey period and stayed at home to give birth in the last decade. Studies showed that rich wealth status women were more likely to deliver at health facilities than the poor ones. ${ }^{28} 2932$

Furthermore, access to health facilities with less distance had a positive contribution to health facility delivery. This study showed that Ethiopia is working hard to improve access to health services over the last decade and that positively contributed to the decline of home delivery. Distance from health facilities was the main problem that influence women to give birth at home. ${ }^{1720293035}$ Ethiopia disease prevention policy has stepped up work on expanding health facilities to achieve access to primary healthcare.

The decline of rural residence among women was insignificant in the last decade and posed a negative effect on home delivery reduction. This finding is supported with different studies women living in rural areas gave birth at home than those living in urban settings. ${ }^{172029} 35$ The possible justification might be that women living in rural areas could not access health facilities easily due to distance.

Controlling the effects of endowment characteristics, about $61 \%$ of home delivery reduction was contributed by behaviour change to the place of delivery. Significant positive and negative contributions to behaviour change in terms of religion, birth order and antenatal care visits were noted.

Changes in behavioural characteristics of women in the Protestant sect had a negative effect that could be made ascertain by the fact that the percentage of Protestant women giving birth at the health facility was low. But no documented evidence states Protestant religion as a barrier to the place of delivery. Thus, further studies are needed on this issue. 
This study indicated that about one-fourth of the decrement in home delivery over the last decade was the change in behaviour related to health facility delivery among women who had two and above birth orders. The possible reason might be women with high birth order experienced different maternal healthcare services and had adequate health education from the healthcare personnel.

Another incredible factor that positively contributed to the decline to home delivery preceding the survey was antenatal care visits. Women who received antenatal care during pregnancy were more likely to give birth at the health facility compared with their counterparts. ${ }^{29} 3637$ Women who had antenatal visits might have obtained health education about the importance of health facility delivery from healthcare professionals which might have changed their behaviour towards health facility delivery.

Since this study encompasses three waves of nationally representative demographic and health survey data, which could enhance the generalisability of the findings. Also, multivariate decomposition logistic regression analysis used to identify factors that positively or negatively contributed to the decline of home delivery in Ethiopia could help policymakers to design interventions. However, the study limitation needs to be considered when interpreting results. One limitation of this study could be recall and social desirability bias as data were collected by a self-reported interview.

\section{Conclusion and recommendations}

In the last decade, home delivery in Ethiopia declined substantially, but this remains unacceptable high. More than one-third of the decrement in home delivery was attributed to the changes in women's compositional characteristics, while two-thirds were attributed to behavioural changes towards health facility delivery over the past 10 years. The compositional change in antenatal care visits, educational status of women and husband, birth order, religion and distance to health facilities were significantly associated with the decline in home delivery. Antenatal care visits, birth order and religion were significantly associated with the home delivery due to coefficients change.

The Ministry of Health and other stakeholders should continue the current effort to increase heath facilitybased delivery through access to healthcare services and strengthen the coverage of antenatal care visits, thereby achieving SDGs goal. The Ministry of Education should strengthen girls' empowerment through education. Researchers need to further explore the barriers of maternal home delivery from religion perspective.

Contributors SAT, ZTT and STY were involved in this study from the inception to design, acquisition of data, data cleaning, data analysis and interpretation and drafting and revising of the manuscript. ALM and MMS were involved in project administration, principal supervision and revising the final manuscript. All authors read and approved the final manuscript.

Funding The authors have not declared a specific grant for this research from any funding agency in the public, commercial or not-for-profit sectors.

Competing interests None declared.
Patient consent for publication Not required.

Ethics approval The authors had submitted a concept note to Demographic and Health Surveys(DHS) programme/ICF International, and permission has been issued by the International Review Board of DHS programme data archivists to download the dataset for this study.

Provenance and peer review Not commissioned; externally peer reviewed.

Data availability statement Data are available on reasonable request. The data were available from the corresponding author, and we can provide on reasonable request.

Open access This is an open access article distributed in accordance with the Creative Commons Attribution Non Commercial (CC BY-NC 4.0) license, which permits others to distribute, remix, adapt, build upon this work non-commercially, and license their derivative works on different terms, provided the original work is properly cited, appropriate credit is given, any changes made indicated, and the use is non-commercial. See: http://creativecommons.org/licenses/by-nc/4.0/.

\section{ORCID iDs}

Sofonyas Abebaw Tiruneh http://orcid.org/0000-0001-5867-5105

Ayenew Molla Lakew http://orcid.org/0000-0003-3648-9891

\section{REFERENCES}

1 World Health Organization. Maternal mortality fact sheet. Matern Heal 2015;2015:1-5.

2 Alkema L, Chou D, Hogan D, et al. Global, regional, and national levels and trends in maternal mortality between 1990 and 2015, with scenario-based projections to 2030: a systematic analysis by the un maternal mortality estimation Inter-Agency group. Lancet 2016;387:462-74.

3 WHO, UNICEF, UNFPA, World_Bank_Group, UNPD. Trends in maternal mortality: 1990 to 2015 executive summary. Publ WHO $2015 ; 14$.

4 Institute of Medicine. Improving birth outcomes: meeting the challenge in the developing world. Washington, DC: The National Academies, 2003.

5 Tessema GA, Laurence CO, Melaku YA, et al. Trends and causes of maternal mortality in Ethiopia during 1990-2013: findings from the global burden of diseases study 2013. BMC Public Health 2017;17:1-8.

6 World Health Organization. Trends in maternal mortality 1990 to 2015. estimates developed by who, UNICEF, UNFPA and the world bank. 96, 2015.

7 Johnston R. The 2030 agenda for sustainable development, 2016: 12-14.

8 Manuscript A. Europe PMC funders group global, regional, and national levels and causes of maternal mortality during $1990-2013$ : a systematic analysis for the global burden of disease study 2013 2014;384:980-1004.

9 Khan KS, Wojdyla D, Say L, et al. WHO analysis of causes of maternal death: a systematic review. Lancet 2006;367:1066-74.

10 Say L, Chou D, Gemmill A, et al. Global causes of maternal death: a WHO systematic analysis. Lancet Glob Health 2014;2:e323-33.

11 Callister LC, Edwards JE. Sustainable development goals and the ongoing process of reducing maternal mortality. J Obstet Gynecol Neonatal Nurs 2017;46:e56-64.

12 World Health Organization. Skilled attendants at birth [online], 2018. Available: https://www.who.int/gho/maternal_health/skilled_care/ skilled_birth_attendance_text/en/

13 UNFPA. Trends in maternal health in Ethiopia. in-depth anal EDHS 2000-2011, 2012.

14 Central Statistical Agency (CSA) [Ethiopia] and ICF. Ethiopia demographic and health survey 2016. Addis Ababa, Ethiopia and Rockville, Maryland: CSA and ICF, 2016.

15 Worku AG, Yalew AW, Afework MF. Factors affecting utilization of skilled maternal care in Northwest Ethiopia: a multilevel analysis. BMC Int Health Hum Rights 2013;13:20.

16 Yebyo H, Alemayehu M, Kahsay A. Why do women deliver at home? multilevel modeling of Ethiopian national demographic and health survey data. PLoS One 2015;10:e0124718-14.

17 Kebede A, Hassen K, Nigussie Teklehaymanot A. Factors associated with institutional delivery service utilization in Ethiopia. Int $J$ Womens Health 2016;8:463-75.

18 Huda TM, Chowdhury M, El Arifeen S, et al. Individual and community level factors associated with health facility delivery: a cross sectional multilevel analysis in Bangladesh. PLoS One 2019;14:e0211113-13. 
19 Bishanga DR, Drake M, Kim Y-M, et al. Factors associated with institutional delivery: findings from a cross-sectional study in Mara and Kagera regions in Tanzania. PLoS One 2018;13:e0209672-15.

20 Habte F, Demissie M. Magnitude and factors associated with institutional delivery service utilization among childbearing mothers in Cheha district, Gurage zone, SNNPR, Ethiopia: a community based cross sectional study. BMC Pregnancy Childbirth 2015;15:403-12.

21 Powers DA, Yoshioka H, Yun M-S. Mvdcmp: multivariate decomposition for nonlinear response models. Stata $J$ 2011;11:556-76.

22 Millennium T, Goals D. The millennium development goals report 2012, 2012

23 Jann B. The Blinder-Oaxaca decomposition for linear regression models. Stata J 2008;8:453-79.

24 Sinning M, Hahn M, Bauer TK. The blinder-oaxaca decomposition for nonlinear regression models. Stata J 2008;8:480-92.

25 Bartus T. Marginal effects and extending the blinder-oaxaca decomposition to nonlinear models. Present 12th UK Stata users GR meet (1-20), 2006.

26 Ethiopia CNPC and the UN. Millennium development goals report 2014 Ethiopia, 2015.

27 ECA, AU, UNDP, AfDB. Assessing progress in Africa toward the millennium development goals: ethiopia's recent MDG performance, 2015.

28 Kamal SMM, Hassan CH, Alam GM. Determinants of institutional delivery among women in Bangladesh. Asia Pac J Public Health 2015;27:NP1372-88.

29 Mekonnen ZA, Lerebo WT, Gebrehiwot TG, et al. Multilevel analysis of individual and community level factors associated with institutional delivery in Ethiopia. BMC Res Notes 2015;8:1-9.
30 Weldemariam S, Kiros A, Welday M. Utilization of institutional delivery service and associated factors among mothers in North West Ethiopian. BMC Res Notes 2018;11:194.

31 Doctor HV, Nkhana-Salimu S, Abdulsalam-Anibilowo M. Health facility delivery in sub-saharan Africa: successes, challenges, and implications for the 2030 development agenda. BMC Public Health 2018;18:1-12.

32 Noh J-W, Kim Y-M, Akram N, et al. Impact of socio-economic factors and health information sources on place of birth in Sindh Province, Pakistan: a secondary analysis of cross-sectional survey data. Int $J$ Environ Res Public Health 2019;16:932-10.

33 Shigute T, Tejineh S, Tadesse L. Institutional delivery service utilization and associated factors among women of child bearing age at Boset Woreda, Oromia regional state, central Ethiopia. J Womens Health Care 2017;06.

34 Ministry of Education. Ethiopian education development roadmap an integrated executive summary, 2018.

35 Bedilu K, Niguse M. Delivery at home and associated factors among women in child bearing age, who gave birth in the preceding two years in Zala Woreda, southern Ethiopia. J Public Health Epidemiol 2017;9:177-88.

36 Fekadu GA, Kassa GM, Berhe AK, et al. The effect of antenatal care on use of institutional delivery service and postnatal care in Ethiopia: a systematic review and meta-analysis. BMC Health Serv Res 2018;18:1-11.

37 Boah M, Mahama AB, Ayamga EA. They receive antenatal care in health facilities, yet do not deliver there: predictors of health facility delivery by women in rural Ghana. BMC Pregnancy Childbirth 2018;18:1-10. 